\title{
Multiprofessional working interprofessional learning and primary care: A way forward?
}

\section{ABSTRACT}

\section{KEY WORDS}

multi professional learning; primary care; workforce innovation

Across all sectors of health and social care there is a growing need for collaboration between professionals, agencies, providers and above all with the people they seek to serve. The significant challenge is how to create, within the existing and future workforce, the capability to work in multi professional teams capable of effective collaboration. The intention of this paper is to explore the implications that multi- or more specifically inter-professional learning may have for collaboration within primary care. As part of this, the state of the current evidence base regarding this form of learning will be explored. However, just as this way of learning is but one element in a wider picture of health care, so the focus will also include the implications for a workforce relevant to future primary care.

Received 29 November 2006

Debra Humphris

Director

Health Care Innovation Unit University of Southampton Hants, UK

\section{INTRODUCTION}

In 1988 the World Health Organisation (WHO) identified multi professional education, not as an end in itself, but as a means to ensure that a variety of health professionals could work together to meet the health needs of the people. The Report also made two other important observations: one that there was a growing emphasis on team work within service delivery; and two, the need for a greater com-

Accepted 26 June 2007

munity orientation to ensure that the competencies of the workforce are relevant to the health needs of a population. Both of these themes will be explored further in this paper.

This discussion is also located within the context of the significant health challenges facing health care systems across the globe and the potential consequences, not only for how existing professionals work together, but for the make up of that workforce.

The intention of this paper is to explore the implications that multi or more specifically interprofessional learning may have for collaboration within primary care. As part of this, the state of the current evidence base regarding this form of learning will be explored. However, just as the WHO saw this way of learning as one element in a wider picture of health care, so the focus will also include the implications for a workforce relevant to the future of primary care. 


\section{CONTEXT OF POPULATION NEED}

The growing complexity and demands upon primary care services are well illustrated by the impact of chronic disease. In the UK it has been estimated that up to $80 \%$ of primary care consultations are with people with long term conditions (Singh 2005). The Department of Health in England has estimated that around 17.5 million people are living with a chronic illness (Department of Health 2004). The introduction by the Department of Health of a range of National Service Frameworks has focused on improving services for people with long term conditions. Within these frameworks is a strong emphasis on shifting greater management and delivery of services to primary care (Department of Health 1999; Department of Health 2000b; Department of Health 2001). In Australia it has been estimated that chronic disease is responsible for around $80 \%$ of the total burden of disease, mental problems and injury (Australian Institute of Health and Welfare 2001). The additional challenge of the Australian context is delivering services in remote and rural settings where the availability of health care professionals is far scarcer then in the urban setting.

The WHO has identified the immense and growing burden of chronic disease as among the world's leading causes of death and disability, and it predicts that chronic diseases are likely to result in an even greater burden over the next decade (World Health Organization 2005a). The impact of chronic diseases has been viewed as the major challenge for health care systems in the 21st century (Pruitt \& Epping-Jordan 2005). As the delivery of services to support people with chronic disease has seen a shift from hospital to community and primary care based services, so there has been a growing emphasis on multidisciplinary and intersectoral approaches (World Health Organisation 2006). Given the often complex needs of individuals with chronic diseases a team based approach to care delivery is seen as the most appropriate approach (World Health Organisation 2006). As a consequence, this has implications for the ways in which health care professionals are provided with opportunities to learn about working in an interprofessional team. This should be contextualized within a shift from the traditional model of acute hospital inpatient care to a more community based self care management model of care (Institute of Medicine 2004). In response to these workforce challenges the WHO developed five basic competencies for health care professionals aimed at enhancing the delivery of effective care for people with chronic conditions (World Health Organisation 2005b). These are:

- Patient centered care;

- Partnering;

- Quality improvement;

- Information and communication technology;

- Public-health perspective.

The detail of the competency related to partnering, in particular, highlights the need for health care professionals to be egalitarian and inclusive in decision-making between themselves and with their patients (Pruitt \& EppingJordan 2005). In order to be able to do this they need to be able to develop the capability to work in teams and collaborate. The team should comprise the person who is the focus of care as well as other providers of care involved with that person's care. Here again this raises the need to create learning opportunities for practitioners, at all stages of their careers, to develop their competency to work in multiprofessional teams in order to enhance collaboration. The commitment to such educational innovation should equally be mainstreamed within relevant curriculum.

\section{Semantics AND EVIDENCE}

There has been considerable discussion in the literature about the terms used to describe or differentiate occasions when individuals of differing professions come together to learn. 
Multiprofessional can be taken to describe occasions when a range of people come together in a mixed group to learn the same content, for example staff attending a lecture on research methods. Interprofessional learning describes occasions when two or more professions come together to learn with, and from, each other with the intention of promoting collaborative practice (Barr 1996). For the purpose of this paper the term interprofessional education (IPE) will be used and is taken to denote opportunities when two or more professions learn with, from and about each other in order to enhance collaborative practice (Barr 2000; O’Halloran et al. 2006). Central to any such endeavour is the intention to build relations between professionals to enhance the quality and responsiveness of the services they deliver.

Over the past thirty years considerable efforts have been invested in attempts to assemble the available evidence relating to IPE. Much of that evidence to date has been produced by small scale interventions based in a range of settings. An early attempt was made to assemble the available evidence of the effect of IPE on organisational or patient outcomes using the Cochrane Collaboration standards for systematic reviews. Unsurprisingly this review identified the lack of evidence based on designs involving a randomized controlled trial, before and after studies, or interrupted time series studies (Zwarenstein et al. 1999). For Barr et al. (2000) the lack of such evidence illustrated at that time that arguments in favour of IPE, while persuasive, could not be substantiated. Using a modified systematic review of studies, Cooper et al. (2001) focused on pre registration education (1994-1999). Based on qualitative and quantitative methodologies they found that the major effects were upon students' knowledge, attitudes, skills and beliefs about professional role and team working and that positive attitudes towards interprofessional practice were founded on early learning experiences. From the studies included in the review the majority of interventions took place in academic or community settings and were focused on team work in primary health care. The dilemma, as ever, is that the absence of evidence does not equate to the absence of proof rather it illustrates that without innovation evidence cannot be developed (Humphris \& Macleod Clark 2002).

A major study in the National Health service (NHS) in England involving qualified professionals provided clear evidence that effective interprofessional team working can improve communication, cost-effectiveness and efficiency of care and outcomes for people (Borrill et al. 2000); thereby endorsing the point that it is the differing perspectives of the various members of a team that makes collaborative work more powerful than working separately (Davies 2000). Five years on from his analysis, Barr (2005) undertook a subsequent review with a wider scope in terms of focus and methodologies, from which the evidence suggests that IPE can contribute to improving collaboration in practice (Barr 2005). However, whilst there has clearly been a growth in the evidence generated about the impact of IPE there remains a need to invest in longitudinal studies, especially related to undergraduate experiences of IPE and its subsequent impact upon individual professional practice (Herbert 2005; Humphris \& Hean 2004).

\section{'THERE IS NO VIRTUE LIKE NECESSITY' (SHAKESPEARE)}

One of the more exciting areas of interprofessional education is in the development of rural practice learning opportunities for pre qualifying health professional students. The opportunities and challenges faced by health services in remote and rural settings create a necessity to produce flexible responses to need. The challenge to attract future health care professionals to careers in such settings is a significant challenge for countries such as Australia and Canada (McNair et al. 2005; Romanow 2002). In Australia there have been concerted efforts to increase the opportunities for remote and rural 
placement experiences for students via the establishment of University Departments of Rural Health (Lawson et al. 2000). Historically these have been orientated towards medical programmes but across a number of States and Territories programmes are now evolving to take a wider interprofessional approach. One example from the State of Victoria, has been the Rural Inter Professional Education (RIPE) Project at the University of Melbourne, a three year initiative funded by the State Government, to create IPE placement experiences in rural primary care (McNair et al. 2001). Student volunteers from nursing, medicine; pharmacy and physiotherapy were given the opportunity to apply for a two week rural placement as part of a mixed interprofessional group. The students were organised in to groups of eight or ten and placed in one of four geographical areas.

The project objectives were as follows:

\section{Year 1}

1. Create a positive attitude amongst undergraduate nursing and medical students towards rural practice;

2. Enable students to gain an understanding of rural PHC and communities;

3. Improve students' knowledge of the value of a team approach to PHC delivery;

4. Increase the collaborative skills within the rural workforce by training preceptors in collaborative concepts and actively teaching collaborative skills in an interdisciplinary learning environment at an undergraduate level;

5. Address the imbalance of opportunity of rural community placements for nursing students;

6. Improve the links between rural health practitioners and universities.

\section{Years 2 and 3 and beyond}

1. Include allied health students in the target group;

2. Extend program to urban PHC settings;
3. Incorporate IPE module into core curriculum;

4. Foster research opportunities across participating institutions and disciplines;

5. Develop on-line teaching packages to reach a wider audience in PHC settings;

6. Contribute to increasing the rural workforce, by increasing the number of young graduates who will consider rural practice.

(McNair, Brown, Stone \& Sims 2001)

The project was set up for students to volunteer to undertake a professional experience in a remote or rural setting. Evaluation of the experience illustrated that students reported increased team working skills and, for some, an increased intention to work in the rural setting. The project team recognised a number of limitations including the need for improvements to the program and that the sample of students comprised volunteers. However, based on their evidence, they felt confident to suggest that the model of IPE should be developed and used more widely within Australia (McNair, Stone, Sims \& Curtis 2005).

The major reforms of health services in Canada have also highlighted the importance of transforming the way in which health professions are prepared if they are to be expected to work in teams (Pringle et al. 2000). The Romanow Commission (2002) commented that if there is an expectation for health care to be provided collaboratively by a variety of personnel, then their education and training should prepare them for this type of working arrangement. In response to this, one of the actions of Health Canada has been to support an initiative entitled Inter-professional Education for Collaborative Patient-Centred Practice (IECPCP) (Herbert 2005). The objectives of this investment are to:

- promote and demonstrate the benefits of interprofessional education for collaborative patient-centred practice;

- increase the number of health professionals 
trained for patient-centred interprofessional team practice at the level of entry to practice, graduate education and continuing education;

- stimulate networking and sharing of best educational practices for collaborative patient centred practice.

In pre-empting these developments the University of British Columbia, in response to the very real challenge of recruiting and retaining a workforce in rural health care, has developed a programme to enable pre qualifying students from a range of professions to undertake a team based placement in a remote community. The Interprofessional Rural Programme of British Columbia (IRPbc) provides students with the reality of hands on experience of interprofessional teamwork and the challenges of rural primary care (Charles et al. 2006). IPRbc has been able to increase the understanding of the needs of rural communities and the wider range of factors that are determinates of health. Evidence from evaluations to date indicate that the work of the students is adding value to the communities in which the students are placed, whilst also enabling them to achieve their learning outcomes (Charles et al. 2006).

In Ontario, as part of system reforms, the Ministry of Health has established a Family Health Teams initiative to establish interprofessional teams focused in improving primary care services for communities. For Meuser (2006), this marks a shift from the traditional model of uni professional primary care. The teams will comprise family physicians, nurse practitioners, nurses, pharmacists, social workers and others. The emphasis in this development is to promote collaboration and build mutual respect for the contribution of all members of the teams. Their focus will be to improve the management, prevention and health promotion of individuals with long term conditions. The assumption behind this development is that Family Health Teams will enable primary care services to become more co-ordinated and increase the level of care (Meuser et al. 2006). The clear and explicit emphasis to create effective interprofessional teams will see the practitioners involved being supported to learn with, from and about each other. Here again is a specific attempt to support teams to develop mutual respect and value the contribution of each other to the delivery of the care of people.

\section{WidER COlLabORATIVE IMPLICATIONS}

The growing challenges for primary care services, as the WHO recognised, will require effective team based approaches to service delivery. However, more effective teamwork between existing professionals is unlikely to be enough to meet the health and well being needs faced by communities.

Whilst improving interprofessional learning can deliver better understanding and mutual respect for the contribution of relevant professionals and improve patient outcomes (Borrill et al. 2000), this does not necessarily mean that the skill mix of a team is appropriate to meet the needs of service users, or indeed makes best use of the skills of those professionals. Examining the existing professional demarcations of work can reveal significant opportunities to rethink not only what the patient needs are, but importantly what services are needed and what roles are required to deliver those services.

New roles within the workforce are already emerging in response to changing needs and one such example is the delivery of intermediate care services in England. The development of intermediate care has been a key area for service modernisation within the NHS Plan (Department of Health 2000a) and the National Service Framework for Older People (Department of Health 2001). This policy has seen the development of multidisciplinary teams providing short periods of intensive rehabilitation services aimed at supporting people in their own homes. In order to deliver these changes, it 
has been necessary to support and develop multidisciplinary teams to develop differing ways of working.

Similar to many other countries, changes in the population profile in the United Kingdom will see an increase of almost 300\% in the very old over the next 50 years (The Royal Commission on Long Term Care 1999) Therefore, in the face of the likely expansion of health and social care needs of many populations and the growing complexity of the care required, the challenge for health and social care services will be to respond and develop comprehensive services that are focused on these evolving needs. In responding to these demands service providers will by necessity need to develop appropriate workforce models that not only enable the delivery of services but that are also appropriate to local labour market conditions.

The publication of the National Service Framework for Older People identified intermediate care as a key element in modernising service for older people, setting out a range of service delivery targets (Department of Health 2001). Whilst it has been acknowledged that the term 'intermediate care' has no clear agreed definition (MacMahon 2001), in a review of the literature Steiner (2001: 33) identified a number of themes that reflect that such services are seen as 'supportive rather than directive', reflect a model of care more akin to nursing than medicine, and that care delivery is focused in or near to the patient's home setting.

Whilst the models of service provision that characterise intermediate care are likely to vary from setting to setting, a range of services and delivery modalities may be involved, including rapid response team, GP nursing home beds, nurse led units, hospital at home schemes, social service rehabilitation, community hospitals, community care centres and hospital beds (Steiner 2001). The range and complexity of interrelated services highlights the need to take a 'whole systems' approach to the development and provision of such services. The multi profes- sional mix of Intermediate care teams, and the evolving use of support workers has been described as vertical and horizontal substitution (Nancarrow 2004). Both forms of substitution illustrate the exchange and transfer of tasks either between registered practitioners and support staff (vertical) or between differing professional groups (horizontal). One consequence of exploring these territories of overlap is the opportunity to reconsider and re-align the workforce to respond to the changing needs of clients and the wider population. But here again at the heart of service delivery is an emphasis on effective team based care relevant to the needs of the community.

\section{CONCLUSION}

Across all sectors of health and social care there is a growing need for more collaboration between professionals, agencies, providers and above all with the people they seek to serve. The significant challenge is how to create, within the existing and future workforce, the capability to work in multi professional teams capable of effective collaboration. The development of such capability clearly necessitates changes in how we prepare that workforce. In the remote and rural setting primary care provides a veritable 'hothouse' of innovation and learning about collaboration. However, the scale of challenges facing health systems will not be addressed by simply improving the collaborative practices between existing healthcare practitioners. There will also need to be a serious examination of the workforce that is necessary and relevant to the needs of communities. As the demands for services increase so the workforce will need to continue to evolve, new forms of practitioner and new forms of care delivery are inevitable. Developing the capability for multi professional working is only one means to deliver the end which remains a flexible and responsive workforce.

\section{References}

Australian Institute of Health and Welfare (2001) 
Chronic Diseases and Associated Risk Factors in Australia, Australian Institute of Health andWelfare, Canberra, PHE-33.

Barr H (1996) Ends and means in interprofessional education: Towards a typology, Education Health 9(3): 341-351.

Barr H (2000) Interprofessional education: 1997-2000 a review, CAIPE, London.

Barr H (2005) Interprofessional education: Today, yesterday and tomorrow a review, Learning \& Teaching Support Network: Subject Centre for Health Sciences \& Practice, London.

Barr H, Freeth D, Hammrick M, Koppel I and Reeves S (2000) Evaluations of interprofessional education, Centre for the Advancement of Interprofessional Education \& the British Educational Research Association.

Borrill C, West M, Shapiro D and Rees A (2000) Team working and effectiveness and health care, British Journal of Health Care Management 6: 364-371.

Charles G, Bainbridge L, Copeman-Stewart K, Art ST and Kassam R (2006) The Interprofessional Rural Program of British Columbia (IRPbc), Journal of Interprofessional Care 20(1): 40-50.

Cooper H, Carlisle C, Gibbs T and Watkins C (2001) Developing an evidence base for interdisciplinary learning: a systematic review, Journal of Advanced Nursing 35(2): 228-237.

Davies C (2000), Getting health professionals to work together: There's more to collaboration than simply working side by side, British Medical Journal 320: 1021-1022.

Department of Health (1999) National service framework for Diabetes, Department of Health, London.

Department of Health (2000a) The NHS Plan, Department of Health, London, Cm 4818-I.

Department of Health (2000b) National service framework for Coronary Heart Disease, Department of Health, London.

Department of Health (2001) National service framework for older people, Department of Health, London.

Department of Health (2002) National Service Framework for Older People: Intermediate care moving forward, London, Department of Health.
Department of Health (2004) Improving chronic disease management. A note for PCT, NHS Trust and SHA management teams.

Herbert CP (2005) Changing the culture: Interprofessional education for collaborative patient-centred practice in Canada, Journal of Interprofessional Care 19(2): 1-4.

Humphris D and Hean S (2004) Educating the future workforce: building the evidence about interprofessional learning, Journal of Health Services Research and Policy 9(1): 24-27.

Humphris D and Macleod Clark J (2002) Shaping a vision for a 'new generation' workforce, Institute for Public Policy Research, London.

Institute of Medicine (2004) Improving medical education: enhancing the behavioural and social science content of medical school curricula, National Academies Press for the Institute of Medicine, Washington DC.

Lawson KA, Chew M, Van Der Weyden M (2000) A revolution in rural and remote Australia: Bringing health education to the bush, Medical Journal of Australia 173: 618-624.

MacMahon D (2001) Intermediate care - A challenge to specialty of geriatric medicine or its renaissance? Age \& Ageing 30(3): 19-23.

McNair R, Brown R, Stone N and Sims J (2001) Rural interprofessional education: Promoting teamwork in primary health care education and practice, Australian Journal of Rural Health 9: S19-S26.

McNair R, Stone N, Sims J and Curtis C (2005) Australian evidence for interprofessional education contributing to effective teamwork preparation and interest in rural practice, Journal of Interprofessional Care 19(6): 579-594.

Meuser J, Bean T, Goldman J and Reeves S (2006) Family health teams: A new Canadian interprofessional initiative, Journal of Interprofessional Care 20(4): 436-438.

Nancarrow S (2004) Dynamic role boundaries in intermediate care services, Journal of Interprofessional Care 18(2): 141-151.

O'Halloran C, Hean S, Humphris D and Macloed Clark J (2006) Developing common learning: the New Generation Project undergraduate curriculum model, Journal of Interprofessional Care 20(1): 12-28. 
Pringle D, Levitt C, Horsburgh M, Wilson R and Whittaker M (2000) Interdisciplinary collaboration and primary health care reform, Canadian Family Physician 46: 763-765.

Pruitt SD and Epping-Jordan JE (2005) Preparing the 21 st century global healthcare workforce, British Medical Journal 330: 637-639.

Romanow R (2002) Building on values: The future of health care in Canada. Final report of the Commission of the Future of Health Care in Canada, Health Canada, Ottawa.

Shakespeare W (2005) King Richard the Second 1st World Library Ltd, London.

Singh D (2005) Transforming chronic care: A systematic review of the evidence, EvidenceBased Cardiovascular Medicine 9(2): 91-94.

Steiner A (2001) Intermediate care - a good thing? Age and Ageing 30: 33-39.

The Royal Commission on Long Term Care (1999) With respect to old age:long term careRights and responsibilities, The Stationery Office, London, Cm 4192.
World Health Organisation (1988) Learning together to work together for health. Report of a WHO Study Group on Multiprofessional Educaton of Health Personnel and the Team Approach, World Health Organisation, Geneva, 796.

World Health Organization (2005a) Preventing chronic diseases: a vital investment, World Health Organization, Geneva.

World Health Organisation (2005b) Preparing a Health CareWorkforce for the 21st Century: The Challenge of Chronic Conditions, World Health Organisation, Geneva.

World Health Organisation (2006) The World Health Report 2006 -Working together for health, World Health Organisation, Geneva.

Zwarenstein M, Atkins J, Hammrick M, Barr H, Koppel I and Reeves S (1999) Interprofessional education and systematic review: a new initiative in evaluation, Journal of Interprofessional Care 13(4): 417-424.

\section{AVAILABLE SOON - FOR 2008 COURSES}

\section{SPECIAL ISSUES IN}

\section{AGED CARE, PALLIATIVE CARE, DEATH AND LOSS}

\section{CONTEMPORARY NURSE}

Advances in Contemporary Palliative and Supportive Care, edited by Annette Street, Carol Tishelman, Jeanine Blackford and Joakim Ohlin (ISBN 0-9757710-4-3; ii + 124 pages; December 2007)

Advances in Contemporary Aged Care: Retirement to End of Life, edited by Margaret McMillan and Isabel Higgins (ISBN 978-0-9757710-3-7; ii + 154 pages; August 2007)

\section{Health Sociology Review}

Death, Dying and Loss in the 21st Century, edited by Allan Kellehear (University of Bath) (ISBN 978-0-9757422-9-7; ii + 102 pages; December 2007)

Course Coordinators are invited to contact the Publisher for an adoption evaluation copy. Student discounts apply. Additional discounts may be negotiated for course pack combinations of any of the above titles.

eContent Management Pty Ltd, PO Box 1027, Maleny OLD 4552, Australia Tel.: +61-7-5435-2900; Fax. +61-7-5435-2911;

subscriptions@e-contentmanagement.com; www.e-contentmanagement.com 